\title{
Study of Parameters Influencing the Performance of Connectors Used for Load and Temperature Tests on Transformers
}

\author{
Salvador Magdaleno-Adame \\ Instituto Tecnologico de Morelia, Michoacan, \\ Mexico \\ J. C. Olivares-Galvan, R.Escarela-Perez \\ Universidad Autonoma Metropolitana, Ciudad de Mexico, \\ D.F., Mexico
}

\begin{abstract}
This paper emphasizes the factors to be considered when designing power connectors used in the load and temperature tests of power transformers. External conductors used to perform load and temperature tests in transformers are referred as power connectors in this contribution. Electrical and thermal investigations of a single-phase shell-type, 300 MVA, $400 \mathrm{kV}-21.5 \mathrm{kV}$ power transformer connector were performed. To analyze the behavior of the connector, a harmonic analysis to calculate losses by Joule effect generated in the electrical connector was first performed, followed by a thermal, finite element based analysis to determine temperature distribution. As heat sources, harmonic losses analyses were performed. Temperature distribution obtained by the finite element simulation was compared with measurements recorded by an infrared camera during the tests.
\end{abstract}

Keywords-Load test, temperature test, contact area, finite element method, electrical conector.

\section{INTRODUCTION}

Power transformer is a very important element in any power system or any particular substation. Transformer manufacturers perform various tests to determine the thermal, mechanical and electrical integrity of the equipment. Tests are also performed to determine the equivalent circuit parameters, which enable implementing them within an electrical system [1], [2].

Among the routine tests that are performed on transformers, load and temperature tests are two of the typical ones. Load test determines the copper losses of the transformer. In this test, voltage is applied to the high voltage terminals, maintaining the low voltage terminals short-circuited. Temperature test determines the temperature rise of the transformer [3], [4]. The duration of temperature test is 12 hours. This test applies a voltage below the nominal voltage at the high voltage terminals, thereby achieving the nominal current in the short-circuited terminals. To short-circuit the

\author{
I. Fofana, L. Loiselle \\ Canada Research Chair, tier 2, on Insulating Liquids and \\ Mixed Dielectrics for Electrotechnology, Université du \\ Québec à Chicoutimi, 555, Boulevard de l'Université, \\ G7H 2B1, Chicoutimi, Qc, Canada \\ P. S. Georgilakis \\ School of Electrical and Computer Engineering, National \\ Technical University of Athens (NTUA), 15780 Athens, \\ Greece
}

low voltage terminals of the transformer, an electrical connector, in which high currents flow (10 to $32 \mathrm{kA}$ ) was used. These sills are assembled with stainless steel screws to prevent hot spots and form a solid conducting body that allows short-circuiting the low voltage bushings.

Proper design of connectors allows avoiding high losses by Joule heating and therefore high temperatures rise during transformer tests. Authors in [8]-[15] emphasized the various factors affecting the performance of a good or bad connection of conductive materials, as well as mitigation measures to be taken into account when choosing conductive materials for electrical connectors. To the best of our knowledge, no studies related to electrical connectors used in transformer tests have been published. No information about their design construction, electromagnetic and thermal effects, failures, costs, etc. are available.

The aim of this paper is to discuss the main factors to be considered for the design of electrical connectors suited for transformers tests. The selection of the type of conductive material of the connector should take into account their mechanical, electrical, thermal, chemical properties.

The electrical properties of materials used in the connectors design are very important. Electrical contact between pieces of conductive material depends on the way the surface is finished, on the contact area and the force with which the connection is made. Another factor to be considered in the design is the type of connection. During transformer tests, joints with stainless steel screws (non-magnetic) are used. Recommended torque of screws $(190 \mathrm{Nm})$ should be considered to obtain a good connection without temperature increases in the areas of the joints and screws.

One way to check if a connection is working properly is to monitor its temperature, since temperatures higher than expected values would indicate problem.

Transformer manufacturers expect connector temperatures below $90^{\circ} \mathrm{C}$, during transformer test. It is not advisable to have temperatures above $90^{\circ} \mathrm{C}$ due to overheating of the parts close 
to the connector, such as low voltage bushings, tank wall, gaskets, and dielectric oil.

Furthermore, connector design should also enable easy disconnection. This is necessary because at the end of the temperature test, the available disconnection time is less than 60 seconds, since at the end of the test, we performed temperature cuts.

\section{DESIGN CONSIDERATIONS FOR AN ELECTRICAL CONNECTOR}

A good connector design will ensure transformer tests reliability. For the design of an electrical connector, several factors including connector material, contact area, and connection types must be considered. In the section, a brief explanation of each of these factors is provided.

\section{A. Material electrical connector}

Conductors used not only for connectors (end for any electrical element) are made of copper and aluminum [8]-[15]. We use these conductors because they have many advantages over others in terms of their chemical, thermal and electrical properties, availability and cost. The best practice for this type of connection is to design connector in the same material as the conductors to be joined, since this eliminates galvanic corrosion.

\section{B. Contact area}

Braunovic [11] advocates that for the good performance of the connector, it is essential to ensure that the contact area is large enough, since, (as shown in Fig. 1), the electric current only passes through the contact points, which will be achieved during connection, to reduce the actual contact area. As the contact force increases, the surface contact points of these metal-metal will increase as a result of the breakdown of the oxide layer and the metal extrusion through ruptures. However, it should be noted that a large force may change the properties of materials and may result in an increased temperature and resistance.

\section{Connection type}

The bolted connectors are used because of their versatility, reliability, low cost and easy to assemble and disassemble. Bolted connections screws should be tightened with a torque wrench to proper torque. Inappropriate torques will increase the temperature of the contact area.

\section{FINITE ELEMENT SiMULATIONS OF ELECTRICAL CONNECTOR}

Harmonic analysis of the electrical connector at $60 \mathrm{~Hz}$ using ANSYS Maxwell software was performed. In this analysis, transformer bushings, copper adapters, sill screws and sill presses were not taken into account.
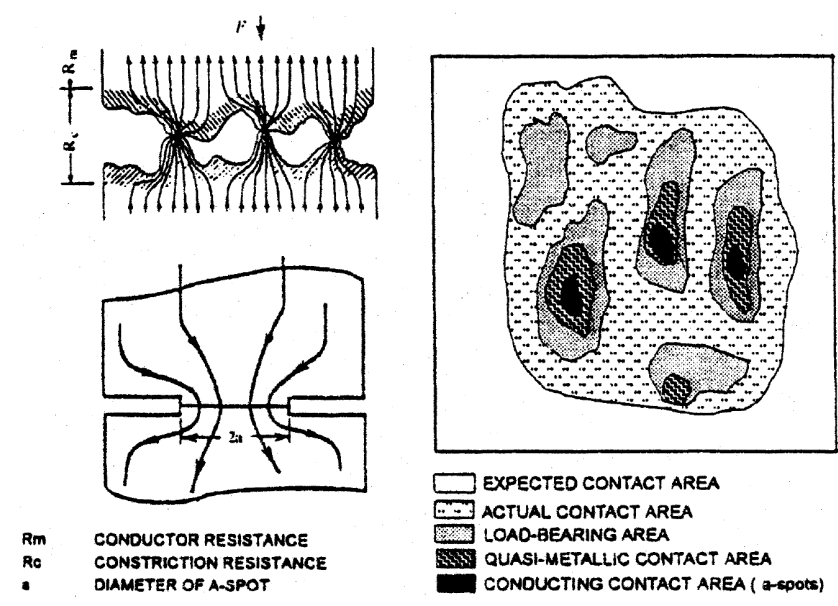

Fig. 1. Real contact area (copyright (C) 2002 IEEE [11], reprinted with permission).

Sills that form the electrical connector are made of copper with a conductivity $\sigma=5.8 \times 10^{7} \mathrm{~S} / \mathrm{m}$; this value was taken from the library of Maxwell ANSYS software.

The peak current value $I$ of the low voltage side of the transformer is:

$$
I=(\sqrt{2})\left(\frac{S}{V}\right)=(\sqrt{2})\left(\frac{300 \mathrm{MVA}}{21.5 \mathrm{kV}}\right)=19.73 \mathrm{kA}
$$

The transformer connector has 8 copper terminals at each ends because each low voltage bushing also has 8 copper adapters, so that the peak current calculated in (1) is divided by 8 . A peak current of $2.47 \mathrm{kA}$ was injected into each of the electrical connector terminals as shown in Fig. 2.

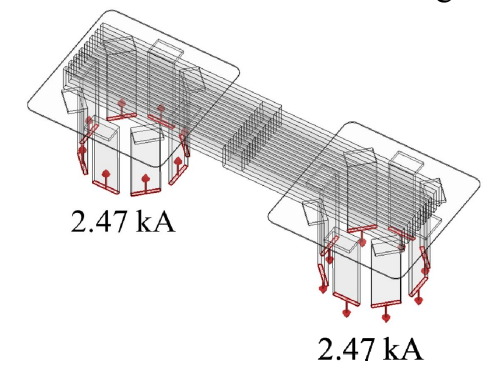

Fig. 2. Load condition of a 300 MVA transformer connector.

The connector model was enclosed in a rectangular parallelepiped whose permeability is $\mu_{o}=4 \pi \times 10^{-7} \mathrm{H} / \mathrm{m}$. In the outer sides of the rectangle is placed a Dirichlet boundary. Fig. 3 shows the connector enclosed in the rectangle of air.

A total of 270,293 pyramidal finite elements throughout the model were used. A fine mesh in each of the sill of the connector was created to take into account the skin effect factor $\delta$ that for copper at $60 \mathrm{~Hz}$ is $8.53 \mathrm{~mm}$. 


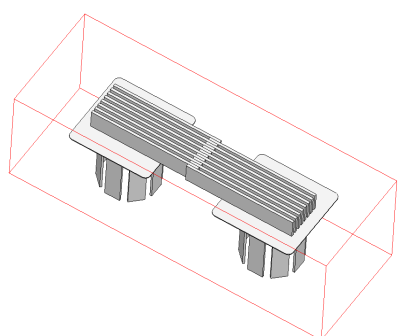

Fig. 3. Connector enclosed in a rectangular parallelepiped.

Fig. 4 shows the finite element mesh used in the electrical connector.

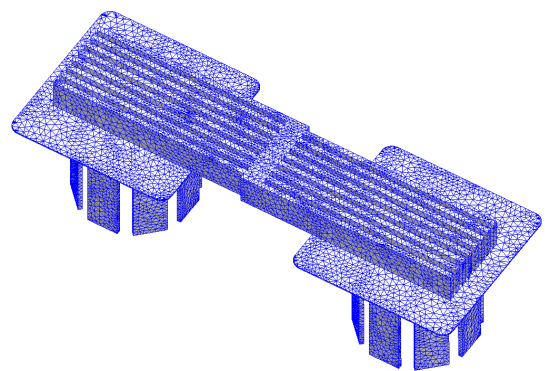

Fig. 4. Finite element mesh of the connector

Fig. 5 shows losses distribution (in $\mathrm{W} / \mathrm{m}^{3}$ ) obtained in the 300MVA transformer connector.

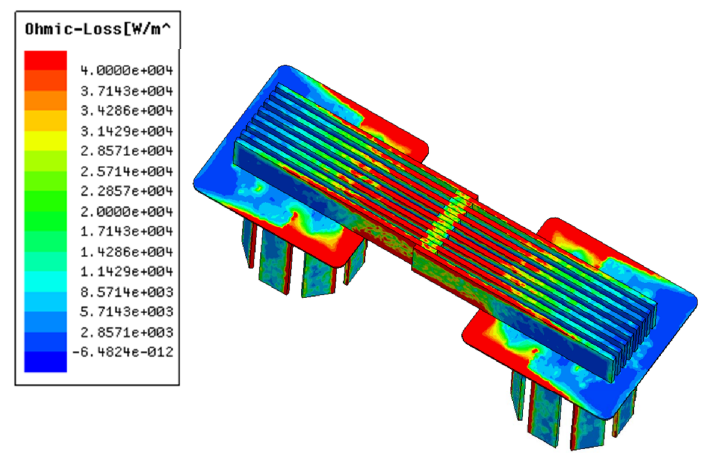

Fig. 5. Loss distribution on the electrical connector (in $\mathrm{W} / \mathrm{m}^{3}$ )

It may be observed that there is a maximum loss of $4 \times 10^{4}$ $\mathrm{W} / \mathrm{m}^{3}$ in the connector sill just before the contact zone. Also in the contact zone of the sill, there is a loss of $2 \times 10^{4} \mathrm{~W} / \mathrm{m}^{3}$. There is less losses in the contact area due to the low current density area and due to the high resistance of the contact zone.

The loss on each connector sill was calculated using [16]:

$$
P=\int_{V} \frac{J \bullet J^{*}}{2 \sigma} d V
$$

where $\mathrm{J}$ is the current density, $\mathrm{J}^{*}$ is the complex conjugate of the current density, $\sigma$ is the conductivity of copper and $V$ the volume of each connector sill [16]. Applying (2) to all the connector sills provides a total loss of $1098 \mathrm{~W}$.

Losses produced by each of the connector sills were used as heat sources for the static thermal analysis. A simulation was carried out on the connector using Comsol Multiphysics software, specifically using the 3D heat transfer module.
In these simulations, connector sills made of copper (thermal conductivity $k=400 \mathrm{~W} / \mathrm{m}^{\circ} \mathrm{K}$, density $\rho=8700 \mathrm{~kg} / \mathrm{m}^{3}$ and specific heat $c=385 \mathrm{~J} / \mathrm{kg}{ }^{\circ} \mathrm{K}$ ) were considered. These thermal properties of copper were taken from the material library of Comsol Multiphysics software. A convection boundary was furthermore applied to all faces upon connector sills. This type of convection boundary was applied to simulate the effect of air cooling by natural convection. A convection coefficient $h$ and ambient temperature $T_{a m b}$ were assigned to this boundary. In the two large square sills at the ends of the connector, a larger convection coefficient (larger than the other sill coefficients) was used since these sills dissipate more heat with larger contact area.

Table I shows the values considered for the convection boundary of the electrical connector.

TABLE I. Values of the convective boundary

\begin{tabular}{|c|c|c|}
\hline Connector sills & $h\left(\mathrm{~W} / \mathrm{m}^{20} \mathrm{C}\right)$ & $T_{\text {amb }}\left({ }^{\circ} \mathrm{C}\right)$ \\
\hline 2 Large square sills & 11 & 25 \\
\hline All other sills & 0.05 & 25 \\
\hline
\end{tabular}

Frank et al. [17] considered values of natural convection of air in the range of 2 to $25 \mathrm{~W} / \mathrm{m}^{2}{ }^{\circ} \mathrm{C}$.

Figure 6 shows the temperature distribution of the connector. The maximum temperature was located around the central-long connector sill, where the average temperature is around $74^{\circ} \mathrm{C}$. Due to Eddy currents, higher temperature appeared near the sills, as shown by the result of the finite element simulation. Furthermore, one can see that there is a high temperature in the contact zone where the joints are made from all copper sills. This area depicts a maximum temperature of $79^{\circ} \mathrm{C}$. It is right here that the higher temperature was expected. In large-square sills, we found an average temperature of $68^{\circ} \mathrm{C}$.

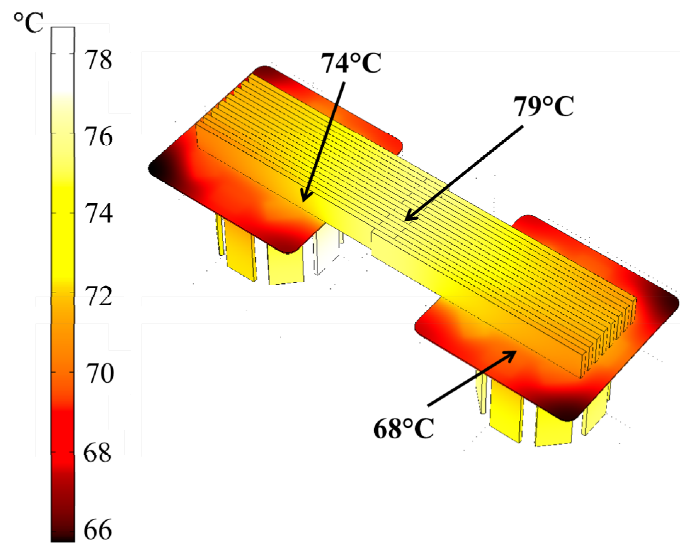

Fig. 6. Temperature distribution of the connector.

Fig. 7 shows the thermal image obtained with the infrared camera for the connector during the temperature test on the 300 MVA transformer.

In fact, the convection coefficients were adjusted in the simulations in a way to achieve a good agreement with the results of the infrared measurement. This is because a static thermal analysis was carried out. For a more complete modeling, an analysis taking into account air to obtain more 
accurate values of convection coefficient of the connector model should be considered. This will be challenge of future work.

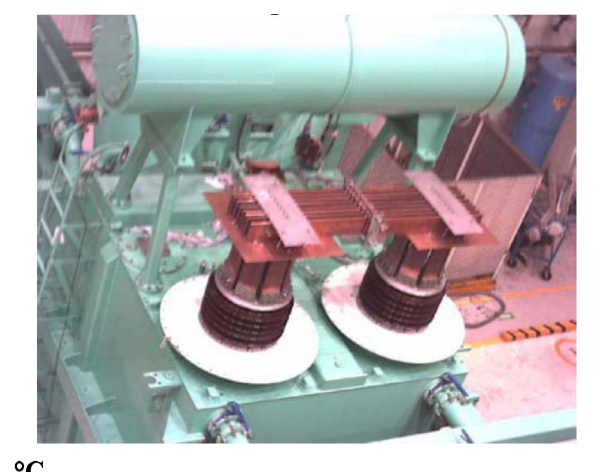

${ }^{\circ} \mathrm{C}$

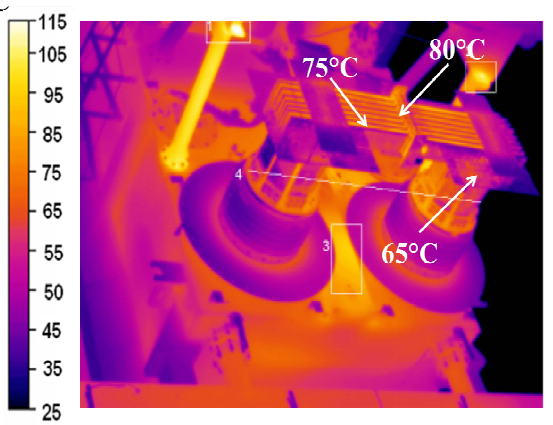

Fig. 7. Connector temperature distribution obtained with the infrared camera.

The temperatures in the finite element simulation are very close to the temperatures measured with the infrared camera. The error between the measured temperature values during the load test of the transformer and those obtained from finite element simulation are less than $5 \%$. This means that the finite element simulation provides a good approximation of actual behavior of transformer connector during the temperature test.

\section{CONCLUSIONS}

An electro-thermal study of electrical connector used in load and temperature tests of a 300 MVA single-phase shelltype transformer was carried out. The simulations results by finite element method and measured values are acceptable from the viewpoint of engineering. Temperatures measured on the electrical connectors are less than $90^{\circ} \mathrm{C}$ as desired by the transformer manufacturer. We obtained good results using the finite element simulation and the temperature distribution obtained with the infrared camera during the actual test of the transformer. The percentages of error between the temperature values measured during the transformer test and those obtained from the finite element simulation were less than $5 \%$.

This paper showed the factors to be considered for the design of electrical connectors. In a future work, it is planned to compare the advantages and disadvantages of manufacturing connectors with sills and stranded conductors, using both copper and aluminum. It is also planned to apply the methodology to higher transformers ratings.

\section{Acknowledgment}

The authors would like to thank Mr. Rodrigo Ocon-Valdez, of Industrias IEM S.A de C.V. for experimental validation and providing design data.

\section{REFERENCES}

[1] S.V. Kulkarni and S.A. Khaparde, Transformer Engineering: Design and Practice, Marcel Dekker, USA, 2004.

[2] P. S. Georgilakis, Spotlight on Modern Transformer Design. Springer, UK, 2009.

[3] IEEE Standard for Standard General, "Requirements for LiquidImmersed Distribution, Power, and Regulating Transformers," IEEE Standard C57.12.00-2006.

[4] H. Nordman and M. Lahtinen, "Thermal overload tests on a 400-MVA power transformer with a special 2.5-pu short time loading capability," IEEE Trans. Power Delivery, Vol. 18, No. 1, Jan. 2003.

[5] A. G. Estrada-Chablé, Juan C. Olivares-Galván, E. Campero-Littlewood, Salvador Magdaleno-Adame, R. Escarela-Pérez, and R. Ocón Valdez, "Analysis of hot-spots on power transformers covers," ALTAE 2011, La Habana, Cuba, 2011.

[6] Y. Junyou, T, Renyuan ,W. Chengyuan, Z. Meiwen, and C. Yongbin, "New preventive measures against stray field of heavy current carrying conductors," IEEE Transactions on Magnetics, May 1996, Volume: 32, Issue: 3, Part 1,pp. 1489-1492.

[7] J. Turowski, "Overheating hazard in flanged bolt joints of transformers," in Proc. Int. Symp. Electromagn. Fields in Elec. Eng., ISEF'85, paper No. 63, pp. 271-274, Warsaw, Poland, 1985.

[8] J. Aronstein and T. K. Hare, "AC and DC electromigration failure of aluminum contact junctions," IEEE Trans. Components and Packaging Technologies, Vol. 28, No. 4, pp. 701-709, Dec. 2005.

[9] M. Runde, H. Jensvold, and M. Jochim, "Compression connectors for stranded aluminum power conductors," IEEE Trans. Power Delivery, Vol. 19, pp. 933-942, July 2004.

[10] M. Braunovic, "Power connections," in Electrical Contacts: Principles and Applications, P. G. Slade, Ed. New York: Marcel Dekker, 1999, pp. $155-277$.

[11] M. Braunovic, "Effect of connection design on the contact resistance of high power overlapping bolted joints," IEEE Trans. Components and Packaging Technologies, Vol. 25, No. 4, pp. 642-650, Dec. 2002.

[12] M. Braunovic, "Fretting damage in tin-plated aluminum and copper connectors," IEEE Trans. Components, Hybrids and Manufacturing Technology, Vol. 12, No. 2, pp. 215-223, June 1989.

[13] R. Frank and C. Morton, "Comparative Corrosion and Current Burst Testing of Copper and Aluminum Electrical Power Connectors," Available at: http://www.copper.org/applications/electrical/building/pdf/A6108.pdf

[14] Piet van Dijk, "Critical Aspects of Electrical Connector Contacts," Available at: http://www.pvdijk.com/pdf/21 thiceccriticalaspects.pdf

[15] Electrical Connections for Power Circuits, Facilites Instructions, Standars, and Techniques FIST 3-3 11/91, August 2000.

[16] Jose A. Rodriguez, "Computation of power losses by stray fluxes in power transformers utilizing the finite element method," (in Spanish) B.Sc. dissertation, UNAM, Mexico, 2008.

[17] Frank P. Incropera and David P. DeWitt, Introduction to Heat Transfer, New York: John Wiley \& Sons, $3^{\text {th }}$ Edition, 1996.

[18] S.W. Kim, H.H. Kim, S.C. Hahn, B.Y. Lee, K.Y. Park, Y.J. Shin, W.P Song, J.B. Kim, and I.H. Shin, "Coupled finite-element-analytic technique for prediction of temperature rise in power apparatus," IEEE Trans. Magnetics, Vol. 38, No. 2, pp. 921-924, March 2002.

[19] Robert T. Coneybeer and W.Z. Black, "Steady-state and transient ampacity of bus bar," IEEE Trans. Power Delivery, Vol. 9. No. 4, pp. 1822-1829, Oct. 1994.

[20] S. Magdaleno Adame, R. Ocon V., A. Rodriguez R, and A. Cancino Quiroz, "Analysis of stray flux in 3D and temperature distribution of shell-type transformers," (in Spanish), RVP-AI/2009-TRO-13, Acapulco, Guerrero, Mexico, July 2009. 